\title{
Residency and Local Connectivity of White Sharks at Liguanea Island: A Second Aggregation Site in South Australia?
}

\author{
RL Robbins $^{1, *}$, M. Enarson ${ }^{1}$, RW Bradford ${ }^{2}$, WD Robbins ${ }^{3}$ and AG Fox ${ }^{1}$ \\ ${ }^{I}$ Fox Shark Research Foundation, 73 Ninth Avenue, Joslin, South Australia 5070; ${ }^{2}$ CSIRO, Oceans and Atmosphere \\ Flagship, GPO Box 1538, Hobart, Tasmania, Australia 7001; ${ }^{3}$ Wildlife Marine, Perth, Western Australia 6020
}

\begin{abstract}
White sharks show a high degree of residency to specific aggregation sites, to which they return regularly over multiple years. Australian research has historically focused on single aggregation areas within each of the southern states where white sharks occur, but other key habitats likely exist and if so, will be important to identify to effectively monitor and protect threatened white shark populations. This study is the first to describe Liguanea Island as a second white shark aggregation site within South Australia, with residency periods and return visits recorded by multiple individuals. Eight sharks were detected at both Liguanea Island and the other known aggregation area in the state, the Neptune Islands, demonstrating movement between these locations. Sustained residency periods were recorded at both sites, although high periodic site fidelity was apparent with many individuals showing preference for the location at which they were tagged. Individual differences in site fidelity and residency patterns were found, although two sub-adult individuals were found to follow similar movement patterns. The implications of white shark movements, and the suggested identification of a second aggregation areas in close proximity are discussed.
\end{abstract}

Keywords: Acoustic telemetry, Carcharodon carcharias, movement, site fidelity, white shark.

\section{INTRODUCTION}

White sharks, Carcharodon carcharias (Linnaeus). are distributed throughout all temperate oceans [1]. Typical of large sharks, white sharks exhibit low fecundity, late age at maturity, slow growth and modest reproductive rates [2-5]. These attributes make them vulnerable to population depletion. Concerns regarding their population status have prompted protection measures across much of their global range, including a listing under the International Union for the Conservation of Nature (IUCN - 'Vulnerable'), and the Convention on International Trade in Endangered Species (CITES - Appendix II). Nevertheless, incidental capture and mortality of white sharks continues around the world $[6,7]$.

White sharks have far ranging migratory patterns [8-12] but show strong seasonal philopatry to specific aggregation sites on a seasonal or annual basis [10-16]. In Australia, satellite and acoustic tagging studies have demonstrated that individual white sharks travel extensively, often along common corridors associated with the $60-120 \mathrm{~m}$ depth zone [1618]. Aggregation areas where individuals regularly revisit have been identified in several southern Australian states $[16,17,19]$. For example, juvenile white sharks in eastern Australia occupy two primary residency sites (Corner Inlet in Victoria, and Stockton Beach in New South Wales) for extended periods of time (an average of 70 days), and seasonally cycle between these areas over multiple years [16]. Similar observations have been made for aggregation sites in

*Address correspondence to this author at the Fox Shark Research Foundation, 73 Ninth Avenue, Joslin, South Australia 5070;

Tel: (08) 8363 1788; E-mail: rachel@sharkfoundation.com the north east Pacific, where individual sharks appear to remain philopatric to specific residency sites over periods spanning decades [20].

In South Australia, white shark research has focused on the Neptune Islands aggregation area. This is a twin island group approximately $30 \mathrm{~km}$ south of the Eyre Peninsula, found in 60-100 m water depth. The Neptune Islands support a large New Zealand fur seal population (approximately 30,000 individuals) and a smaller (c. 50 individuals) breeding population of Australian sea lions [21, 22]. These likely provide a focal point for white sharks during migrations. White sharks regularly visit the Neptune Islands, remaining for periods averaging six days and extending up to 120 days $[14,23,24]$. The Neptune Islands support the only shark cage dive industry in Australia, which has provided a platform for white shark research for over 30 years. From this, a photographic database of white sharks visiting the Neptune Islands has identified specific individuals over several years, suggesting return to the Neptune Islands by some individuals [23].

Despite the focus of research on the Neptune Islands, white sharks are periodically sighted throughout other South Australian waters. It is likely that other key habitats exist where individual sharks may aggregate. Dangerous Reef, approximately $50 \mathrm{~km}$ northeast of the Neptune Islands, is known to be seasonally frequented by white sharks, and is a site at which tagging and tourism efforts were concentrated in the 1980's and 90's [25]. Dangerous Reef supports the largest population of breeding Australian sea lions in Australian waters with an estimated pup count of 709 [26]. Other locations in South Australia host large pinniped populations and might similarly support recurring white shark 


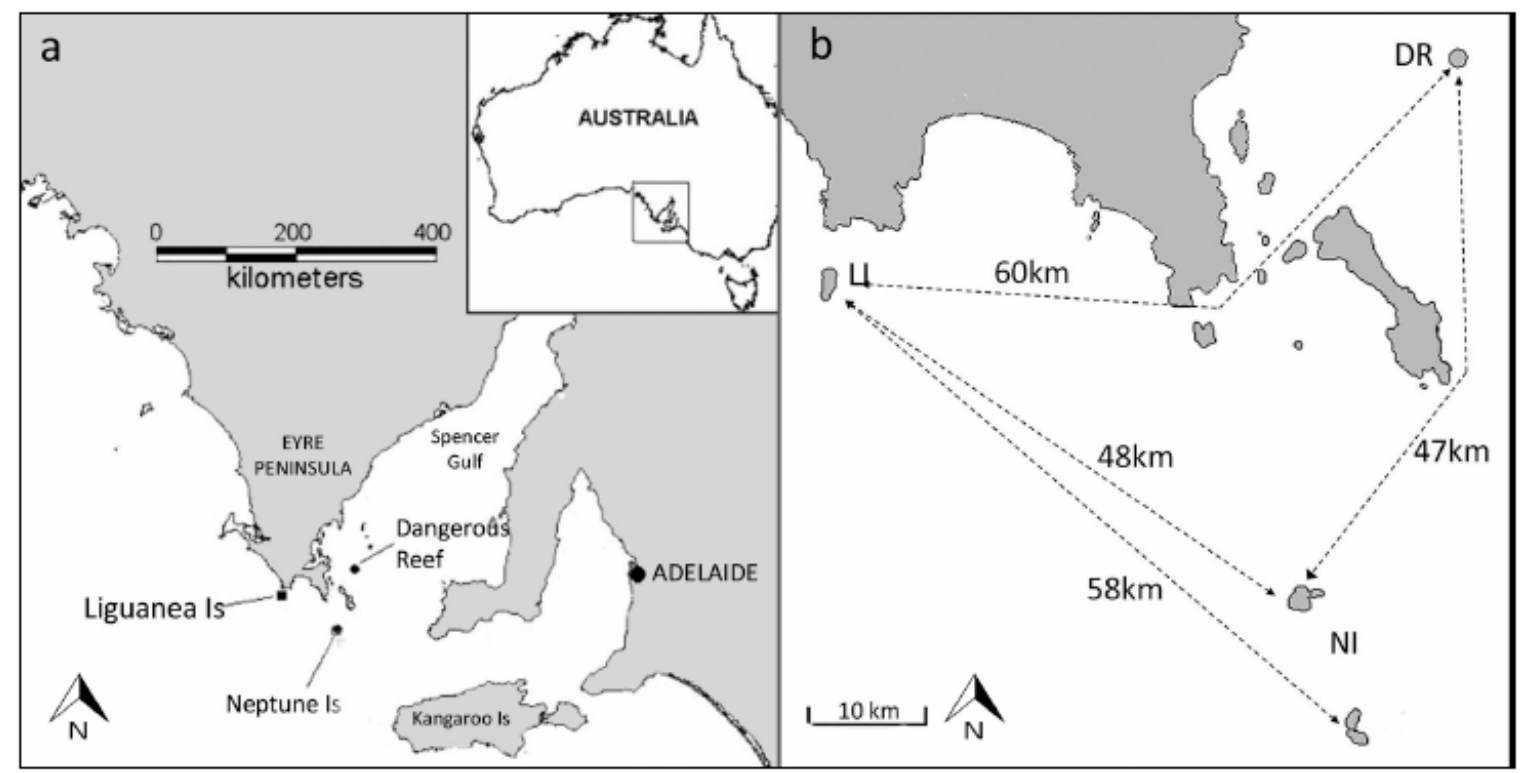

Fig. (1). (a) Location of Liguanea Island in relation to other acoustic receiver deployment sites in South Australia. (b) Distances between the locations calculated as shortest possible travel routes.

aggregations. One such location is Liguanea Island (LI), which lies $47 \mathrm{~km}$ to the southeast of the Neptune Islands group. Liguanea Island shares similar characteristics to the Neptune Islands group, and supports both a large (c. 3000 individuals) breeding population of New Zealand fur seals $[22,27]$ and a smaller (c. 250 individuals) breeding population of Australian sea lions [22]. Commercial fishermen and abalone divers at LI have anecdotally documented interactions with white sharks, however the extent to which sharks use this site remained unknown.

Despite the protected status of white sharks in Australian waters, there is still no mechanism to gauge the efficacy of protection measures. Threats to white sharks exist in many forms, with human-mediated factors including commercial fishing [4], pollution and government shark control programs such as the shark net and drum line (using baited hooks set below moored floats) programs on the east coast $[6,28]$. Defining additional habitat areas frequented by white sharks, and examining the full extent and timing of seasonal movements between such sites and subsequent residency periods is important for the development of protection plans to progress recovery of the population. A better understanding of local shark movements may also assist with the establishment of baseline shark population numbers $[15,29]$. Here we will explore the role LI and DR may play as additional white shark aggregation sites in South Australia. Using acoustic technology, we will examine individual site fidelity and residency patterns, and explore the connectivity between these locations and the only currently recognised aggregation area in South Australia, the Neptune Islands. The role of these sites will be discussed in light of management requirements.

\section{MATERIALS AND METHODOLOGY}

Due to logistical constraints we restricted this study to three island groups where white sharks are known, or have been hypothesized, to frequent (Fig. 1). These islands were also selected as they support similar marine mammal fauna.
Liguanea Island, in the Thorny Passage Marine Park, is found $3.5 \mathrm{~km}$ off the southwest corner of the Eyre Peninsula (Fig. 1). It is a relatively small island $\left(1.2 \mathrm{~km}^{2}\right)$, rising out of waters approximately $60-120 \mathrm{~m}$ in depth. LI has never supported shark cage diving operations (SCDO), however previous observations by the senior author coupled with the presence of pinnipeds suggest LI may be an important region for white sharks in South Australian waters.

The Neptune Islands (NI) group consists of two groups of islands (North Neptune Islands and South Neptune Islands) located approximately $60 \mathrm{~km}$ south of Port Lincoln. The North Neptune Islands $\left(0.98 \mathrm{~km}^{2}\right)$ are the site most used by the shark cage dive operators. The South Neptune Islands $\left(1.04 \mathrm{~km}^{2}\right)$ are situated about $12 \mathrm{~km}$ further south and are occasionally visited by SCDO. The two island groups constitute the Neptune Islands Group Marine Park which covers the waters within two nautical miles of the coastline of both the North Neptune Islands and the South Neptune Islands.

Dangerous Reef (DR) consists of several low-lying $(\sim 3$ $\mathrm{m})$ rocky outcrops Main Reef with nearby East Reef and West Reef, covering about $0.12 \mathrm{~km}^{2}$ in total [30]. Located approximately $30 \mathrm{~km}$ east of Port Lincoln, Dangerous Reef has a history of white shark presence and was a site for SCDO prior to regulations which closed the reef to berley activity in 2005 . However, this site was only seldom used by SCDO and the sparse SCDO logbook data shows only patchy and inconsistent shark presence prior to closure. Together with the limited temporal access to this site (as access was permitted only outside the Australian sea lion breeding season), these factors have limited both the amount of research at this site and assessment of the importance of the site for white sharks.

Under the presumption that white sharks are attracted to the pinniped colonies of each island group we positioned two acoustic receivers (VR2W, Vemco-Amirix) near to the pinniped colonies of each island group in November 2011, allowing simultaneous monitoring of acoustically-tagged 


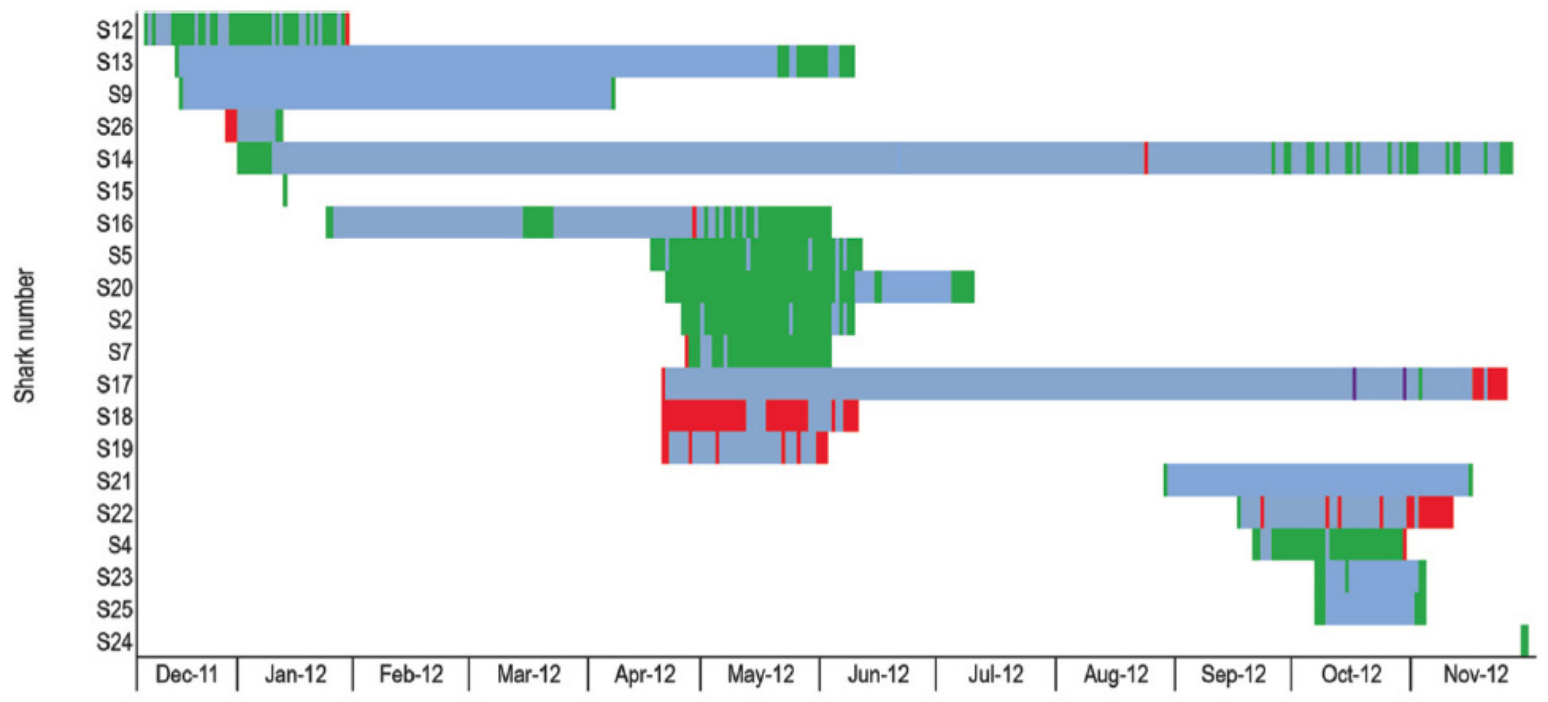

Fig. (2). Residence times (with 1-day vertical bands coloured by locations - LI (red); NI (green); and DR (purple); and periods of absence (blue) of tagged sharks between detections.

white sharks at each location. Receivers were deployed on sub-surface moorings in depths ranging between 15-20 m and were periodically retrieved, downloaded and immediately redeployed during the 12-month study period. Retrieval and redeployment typically required a receiver to be out of the water for about 30 minutes. Previous studies have indicated that the detection envelope for acoustic receivers is dependent on local environmental conditions and can range from approximately $200 \mathrm{~m}$ to a maximum of $1,200 \mathrm{~m}$ [31-33]. Bradford et al. [34] evaluated the use of Vemco acoustic receivers at the Neptune Islands and found the maximum detection envelope was between $300-500 \mathrm{~m}$ at that site. Because the detection envelope does not encompass the entire site, we acknowledge that an absence of detections does not necessarily equate to shark absence.

During shark tagging, free-swimming sharks were attracted to the vessel using berley (a liquid mixture of minced tuna and tuna oil) and "teaser" baits (slices of whole tuna thrown out on a line and hauled back to the boat before being consumed). Tags consisted of acoustic transmitters (V166H-R64K, Vemco-Amirix, 150-162 dB, battery life 6-8 years) tethered to a $32 \times 8 \mathrm{~mm}$ stainless steel dart using 10 $15 \mathrm{~cm}$ of $200 \mathrm{~kg}$ braided stainless steel wire. Tags were affixed to the end of a $2 \mathrm{~m}$ steel pole, and implanted on free swimming white sharks by being rapidly jabbed into the musculature behind the shark's first dorsal fin as the animal passed by the boat. This is a standard method of externally tagging sharks and large marine fishes. The total length (TL) of all individuals was estimated to the nearest $10 \mathrm{~cm}$ by comparison to our research vessel's 6 m-wide dive platform and/or by the use of a digital camera coupled with two lasers parallel mounted $20 \mathrm{~cm}$ apart on a steel rod. The lasers would project two spots onto the shark, providing a known unit of scale for each photograph. The life history stage of individual sharks follows that outlined by Bruce and Bradford [16]: sharks $<300 \mathrm{~cm}$ TL were considered to be immature; males $\geq 300 \mathrm{~cm}$ and $<360 \mathrm{~cm}$ TL were sub-adult, and $\geq$ $360 \mathrm{~cm}$ were mature. For females, those $\geq 300 \mathrm{~cm}$ and $<480$ $\mathrm{cm}$ TL were sub-adult, and females over $480 \mathrm{~cm}$ TL were considered to be mature.
Two periods of site occupancy were defined following parameters described by Bruce and Bradford [24] where 'visits' were defined as the number of consecutive days with detections for an individual shark. Site 'residency period' was defined as the number of days between the first and last detection of a tagged shark when gaps between consecutive days of detection did not exceed five days. When sharks remained undetected for longer than five days, they were assumed to have left the site, and a subsequent detection was considered to be the start of a new period of residency.

\section{RESULTS}

The receivers were active for a total of 357 days at LI and DR, and 370 days at NI. Three sharks were tagged at LI on April $21^{\text {st }}$ 2012. A further 22 sharks were tagged at NI between June 2011 and November 2012. No sharks were tagged at DR during this study. One additional shark was tagged at NI prior to this study and was included due to detections at LI and NI during the study period. A total of 9688 detections were recorded from 20 different tagged sharks ( $71 \%$ of total tagged) during the study period.

A total of ten sharks were detected at LI throughout the study period. This consisted of the three tagged at LI, and seven of the 23 sharks tagged at NI. The length of visits of sharks at LI ranged from 1 to 22 consecutive days (mean $=$ $3.2, \mathrm{SE}=0.9$ ). In addition to the 23 sharks tagged at NI, one shark tagged at LI was also detected at NI (Fig. 2). Visits at $\mathrm{NI}$ ranged from 1 to 27 days $(\mathrm{mean}=4.1, \mathrm{SE}=1.1)$. Two sharks (one tagged at LI and one tagged at NI) were detected on the DR receivers, but both visits were brief, lasting less than 30 minutes (Fig. 2). There was an exchange rate of $31 \%$ $(\mathrm{n}=8)$ between LI and NI for all sharks tagged. These were six males (33\% of total males tagged) ranging from $270 \mathrm{~cm}$ to $450 \mathrm{~cm}$ (TL), and two females $(25 \%$ of total females tagged) measuring $350 \mathrm{~cm}$ and $380 \mathrm{~cm}$ (TL).

The sharks that were tagged at LI spent longer periods of residency at LI than at the other two study sites (Table 1). Six sharks were detected at LI for three days or less, whereas four (including the three tagged there) resided for a longer 
Table 1. Detections, visits and mean residency periods for sharks detected on receivers over the period December 1,2011 to November 30, 2012, sorted according to shark size. Mean residency period shown \pm one standard error. $T L=$ total length (cm); LI = Liguanea Island; NI = Neptune Islands; DR = Dangerous Reef; $D=$ detections; $V=$ visits; $R=$ Residency period. "Residency" means the mean number of days of residency periods.

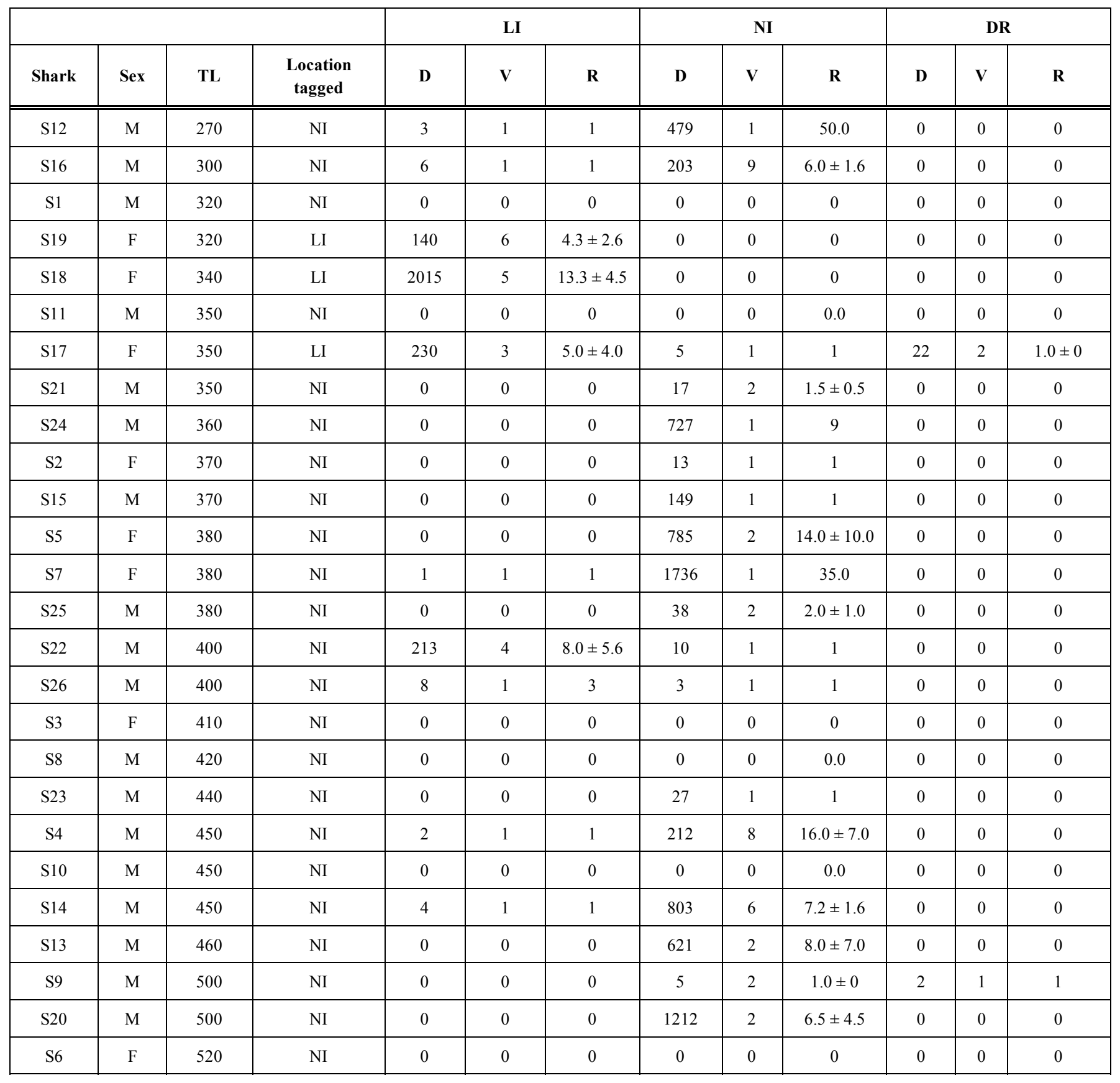

period (Table 1). These longer periods of residency were 22 days, 12 days, 12 days and eight days (resident until final receiver removal - sharks S18, S19, S22 and S17 respectively) (Fig. 2). Two animals (S18 and S19), both sub-adult females, visited LI multiple times over a period of approximately seven weeks, interspersed by non-detection periods of more than five days (Fig. 2). The only shark tagged at NI to exhibit residency at LI (S22) left NI the day after tagging. This animal was not sighted in the previous three days spent attracting and tagging sharks and is presumed to have not been at this site prior to tagging. It was recorded at LI five days later and then made four visits to LI over a period of 49 days (Fig. 2), with 12 days being the longest visit.

A similar pattern of activity was found at NI. Sharks tagged at NI had longer residency periods at NI and only briefly visited LI. Mean residency periods for animals tagged at NI lasted up to 50 days, while only one of the three sharks tagged at LI was detected at NI (for 1.0 days) (Table 1). Five individuals tagged at NI (S7, S16, S18 and S19) were detected at LI between April $21^{\text {st }}$ and $29^{\text {th }}$ (Fig. 2), although three of these were detected for one day only. 
Dangerous Reef did not appear to be a significant residency area for any of the sharks in the study. There were only two sharks recorded at DR (one tagged at NI and one tagged at LI), and both visited only briefly for less than 30 minutes on each occasion (Fig. 2). As no sharks were tagged at DR, we can only speculate on the potential residency of animals encountered here. In this respect, future tagging work at this location may give some useful insights at this location

For some sharks there appeared to be a degree of synchronicity in their arrival and/or departure from a site. For example, two sharks (S7 and S16) departed LI within two days of each other; both were then first detected at NI on the same day where they remained for 33 and 35 days respectively before detections ceased (Fig. 2). Sharks S18 and S19 made multiple visits to LI during the same seven week period, before detections of both ceased on the same day in early June, indicating they departed at the same time. A further six sharks (S2, S5, S7, S13, S16 and S20) resident at NI between April and June 2012 (residency periods ranging from 19 to 54 days) all departed NI over an eight day period between June 3rd and 11th 2012 (Fig. 2).

A single shark (S17, a $350 \mathrm{~cm}$ female tagged April 2012 at LI) was detected at all three island groups during the study period (Table 1; Fig. 2). Following tagging at LI, S17 was detected there over a period of $6 \mathrm{hrs}$ on April $21^{\mathrm{st}}$ after which detections at LI ceased. Six months later in October 2012, S17 was recorded on two separate occasions at DR on the northern receiver. Both occasions were brief, consisting of 10 and 12 detections respectively (over a period of $30 \mathrm{~min}$ utes). Shark S17 was subsequently detected on the NI array $88 \mathrm{~h}$ after departing the DR array. The minimum sea distance between DR and NI is $47 \mathrm{~km}$, representing a potential rate of inter-island movement of $0.14 \mathrm{~m} / \mathrm{s}$. This is well below the typical rate of movement recorded for this species, indicating S17 did not swim directly between these locations, or remained outside the detection range of the receiver. Shark S17 was only detected briefly at NI; the next detection was at LI, $48 \mathrm{~km}$ from NI on November $17^{\text {th }}$ 2012. Again, the potential rate of inter-island movement $(0.03 \mathrm{~m} / \mathrm{s})$ suggests that $\mathrm{S} 17$ did not swim directly between locations.

\section{DISCUSSION}

This study is the first to have installed acoustic receivers and tag white sharks at LI, and to describe visitation and site fidelity of white sharks to this location. Sharks clearly utilise the LI area, with some individuals showing patterns of activity comparable to those found at a nearby recognised aggregation area, the Neptune Islands. We therefore surmise that this location may also be an important aggregation site. The reasons for white sharks utilizing LI may lay both in its location and local fauna: it is found along the $60-120 \mathrm{~m}$ depth contour, which appears to be an important migration depth corridor for travelling adult [17] and juvenile [16, 35] white sharks in Australian waters. This depth range has also been demonstrated as the preferred range for patrolling white sharks at the Farallon Islands [13]. Liguanea Island is therefore likely be encountered by migrating white sharks, and may potentially provide an important layover for migrating sharks. The island also hosts a year-round pinniped popula- tion, which may provide a valuable source of potential food for white sharks $[4,14,17,36]$.

Although there was movement between LI and NI, with $31 \%$ of tagged sharks detected at both locations, individuals appeared to show a distinct preference for residency at one or other location, spending considerably less time at the secondary location when detected. In the North East Pacific, white sharks show similar fidelity to aggregation sites in central California [10,15] and Guadalupe Island, Mexico $[10,37,38]$. While movements between aggregation sites have been previously reported $[10,16]$, adult white sharks predominantly show site fidelity for individual sites over secondary sites $[10,16]$ Similar site fidelity has also been described for juvenile white sharks in along the east coast of Australia. These juveniles show a different pattern, having a small number of preferred residency sites [16] which they cycle between on a seasonal basis. In both the North East Pacific and eastern Australia, residency sites are geographically wide spread (100's km). In the present study the maximum distance between sites was much less. This may indicate that the whole region south of the Eyre Peninsula is an important region for white sharks from the western Australian population; with fine-scale partitioning occurring within the region. Returning to the same site, especially over multiple years, can increase hunting efficiency, by allowing the sharks to learn the most effective sites and hunting strategies to employ $[13,39]$

Sharks may have been undertaking large-scale migrations to their preferred aggregation site when detected at a second site. Four sharks were detected at LI for one day only prior to arrival at NI; and two sharks were detected at LI for one day only after leaving NI. Similarly, the shark tagged at LI that visited NI and DR also did so only briefly. The short visits of sharks to one location just prior to or following a longer residency period at another location may be part of large-scale migrations. Importantly, multiple overlapping individuals displayed this behavior, leading to us deem LI an aggregation area. Brief stops at secondary sites may provide navigational cues or the opportunity to rest and/or feed prior to continuing their journey. Although the SCDO observe sharks at NI throughout the year there is seasonality in the number of sharks present, with winter/spring recording the highest observations. Bruce et al. [17] described the westerly movement of sharks tagged at NI into the Great Australian Bight and Western Australian waters, and suggested a common migration corridor for migrating Australian white sharks similar to that found in the North East Pacific [9, 10]. Other sharks using LI might be showing fine-scale partitioning within the region.

Dangerous Reef did not appear to be a significant residency area for the animals tagged in this study, with two animals only briefly detected. Limited efforts to attract and tag sharks at DR in April and November 2012 were unsuccessful, with no sharks observed in the area at those times. Historical evidence from shark cage diving operator logbooks suggests sharks have used this site in the past, although white shark presence was inconsistent and seasonal (Andrew Fox, unpublished data). Further study needs to be undertaken, with additional focus on periods when naïve pups are first entering the water and most susceptible to pre- 
dation, to determine the extent to which it too could be classified as an aggregation site for white sharks.

Although white sharks are widely dispersed when migrating, their vulnerability to exploitation may be increased at sites at which they aggregate, such as NI and LI. In order to minimize human impacts on white sharks at these aggregation areas, it is essential to understand critical habitat areas in terms of the movements, seasonal variability in abundance, residency periods and site fidelity by individuals at each site. While white sharks are protected from incidental fishing activities at NI by its Sanctuary Zone status, LI lies within a 'Habitat Protection Zone' [40] that allows for "activities and uses that do not harm habitats or the functioning of ecosystems", including extractive processes. It may be that upgrading the protection of key localities at LI to Sanctuary Zone status would afford a larger proportion of the population with a greater level of protection against decline.

Sustained, long-term acoustic monitoring and tagging at these sites could further establish our findings, and assist with predicting activity patterns across a wider geographical area and in establishing baseline population estimates for this population. Further identification of white shark migratory corridors and the potential of other aggregation areas that may lie within such corridors should be a priority to investigate. The existence of further aggregation areas may require management intervention if their location places white sharks in proximity to anthropogenic effects such as commercial fishing operations. In recent years, there has been increased interest in the impact of SCDO on behavior, site fidelity and visitation patterns of white sharks at NI [24, 41]. The data collected from LI in this study, a site at which no berleying activity is undertaken, could be used as a control for comparison with such data from NI. In the meantime, we propose that LI be considered a second aggregation area in South Australia, and this knowledge be taken into consideration for management purposes.

\section{CONFLICT OF INTEREST}

The authors confirm that this article content has no conflict of interest.

\section{ACKNOWLEDGEMENTS}

We would like to thank the Save Our Seas Foundation whose funding made this project possible. We also thank K. Stannard, K. Lee, S. Cahir and the crew of Princess II for their logistical support in the field, and A. Boomer and the team at Australian Animal Tracking and Monitoring System for assistance and technical support in the deployment and maintenance of the receivers. This work has benefited from review by several anonymous reviewers. All research was conducted in accordance with permits from the Department of Environment, Water and Natural Resources, and the Department of Primary Industries and Resources of South Australia. Time on this paper for RWB was supported by the Australian Government's National Environmental Research Program, Marine Biodiversity Hub.

\section{REFERENCES}

[1] Compagno LJV. FAO Species Catalogue. volume 4. Sharks of the World. An Annotated and Illustrated Catalogue of Shark Species
Known to Date. Part 1: Hexanchiformes to Lamniformes. FAO Fisheries Synopsis 1984; 12: 1-655.

[2] Wintner SP, Cliff G. Age and growth determination of the white shark, Carcharodon carcharias, from the east coast of South Africa. Fish Bull 1999; 97(1): 153-69.

[3] Musick JA, Harbin MM, Berkeley SA, et al. Marine, estuarine, and diadromous fish stocks at risk of extinction in North America (exclusive of Pacific salmonids). Fisheries 2000; 25(11): 6-30.

[4] Malcolm H, Bruce, BD, Stevens JD. A review of the biology and status of white sharks in Australian waters. CSIRO Marine Research, Hobart September 2001; p. 81.

[5] García VB, Lucifora LO, Myers RA. The importance of habitat and life history to extinction risk in sharks, skates, rays and chimaeras. Proc R Soc Lond B 2008; 275(1630): 83-9.

[6] Reid DD, Robbins,WD, Peddemors VM. Decadal trends in shark catches and effort from the New South Wales, Australia Shark Meshing Program 1950 to 2010. Mar FW Res 2011; 62(6): 676-93.

[7] Cliff G, Dudley SFJ. Reducing the environmental impact of sharkcontrol programs: A case study from KwaZulu-Natal, South Africa. Mar FW Res 2011; 62: 700-709.

[8] Bonfil R, Meÿer M, Scholl MC, et al. Transoceanic migration, spatial dynamics, and population linkages of white sharks. Science 2005; 310 (5745): 100-3.

[9] Weng KC, Boustany AM, Pyle P, Anderson SD, Brown A, Block BA. Migration and habitat of white sharks (Carcharodon carcharias) in the eastern Pacific Ocean. Mar Biol 2007; 152: 877-94.

[10] Jorgensen SJ, Reeb CA, Chapple TK, et al. Philopatry and migration of Pacific white sharks. Proc R Soc Lond B 2012; 277(1682): 679-88.

[11] Domeier ML. A new life-history hypothesis for white sharks, Carcharodon carcharias, in the northeastern Pacific. In: Domeier M, Ed: Global perspectives on the biology and life history of the Great White Shark. CRC Press 2012; pp. 199-224.

[12] Duffy CA, Francis MP, Manning M, Bonfil R. Regional population connectivity, oceanic habitat and return migration revealed by satellite tagging of white sharks (Carcharodon carcharias) at New Zealand aggregation sites. In: Domeier M, Ed: Global perspectives on the biology and life history of the Great White Shark. CRC Press 2012; pp. 199-224.

[13] Goldman KJ, Anderson SD. Space utilization and swimming depth of white sharks, Carcharodon carcharias, at the South Farallon Islands, central California. Environ Biol Fish 1999; 56: 351-64.

[14] Bruce BD, Stevens JD, Bradford RW. Site fidelity, residence times and home range patterns of white sharks around pinniped colonies. Final report to the Australian Government Department of Environment and Heritage. CSIRO Marine and Atmospheric Research, Hobart, Tasmania 2005; p. 41.

[15] Chapple TK, Jorgensen SJ, Anderson SD, et al. A first estimate of white shark, Carcharodon carcharias, abundance off Central California. Biol Lett 2011; 7(4): 581-3.

[16] Bruce BD, Bradford RW. Spatial dynamics and habitat preferences of juvenile white sharks in eastern Australia. In: Domeier M, Ed. Global perspectives on the biology and life history of the Great White Shark. CRC Press 2012; pp. 225-70.

[17] Bruce BD, Stevens JD, Malcolm H. Movements and swimming behaviour of white sharks (Carcharodon carcharias) in Australian waters. Mar Biol 2006; 150: 161-72.

[18] Werry J, Bruce BD, Sumpton W, Reid D. Preferred beach areas by juvenile white shark, Carcharodon carcharias, in eastern Australia from long-term catch and movement. In: Domeier M, Ed. Global perspectives on the biology and life history of the Great White Shark. CRC Press 2012; pp. 271-86.

[19] Bruce BD, Bradford RW. Spatial dynamics and habitat preferences of juvenile white sharks - identifying critical habitat and options for monitoring recruitment. Final report to the Department of the Environment, Water, Heritage and the Arts. CSIRO Marine and Atmospheric Research, Hobart, Tasmania 2008; p. 71.

[20] Anderson SD, Chapple TK, Jorgensen SJ, Klimley AP, Block BA. Long-term individual identification and site fidelity of white sharks, Carcharodon carcharias, off California using dorsal fins. Mar Biol 2011; 158(6): 1233-7.

[21] Baker JL. Towards a System of Ecologically Representative Marine Protected Areas in South Australian Marine Bioregions. Technical Report. Prepared for Coast and Marine Conservation Branch, Department for Environment and Heritage, South Australia 2004. 
[22] Goldsworthy SD, Page B. A review of the distribution of seals in South Australia. South Australian Research and Development Institute (Aquatic Sciences) 2009, Adelaide, SARDI Publication Number F2009/000368-1; SARDI Research Report Series No. 373.

[23] Robbins RL. Environmental variables affecting the sexual segregation of great white sharks Carcharodon carcharias at the Neptune Islands South Australia. J Fish Biol 2007; 70(5): 1350-64.

[24] Bruce BD, Bradford RW. The effects of shark cage-diving operations on the behaviour and movements of white sharks, Carcharodon carcharias, at the Neptune Islands, South Australia. Mar Biol 2012: 1-19.

[25] Strong WR Jr, Bruce BD, Nelson DR, Murphy RC. Population dynamics of white sharks in Spencer Gulf, South Australia. . In: Klimley AP, Ainley DG, Eds. Great white sharks. The biology of Carcharodon carcharias: Academic Press: San Diego 1996: pp 401-14.

[26] Shaughnessy PD, Goldsworthy SD, Hamer DJ, Page B, McIntosh RR. Australian sea lions Neophoca cinerea at colonies in South Australia: distribution and abundance, 2004 to 2008. Endang Species Res 2011;13(2): 87-98.

[27] Shaughnessy PD. Population assessment of fur seals and sea lions at some colonies in South Australia, 2005-06. Report to Department for Environment and Heritage, South Australia, 2006: p. 33.

[28] Sumpton WD, Taylor SM, Gribble NA, McPherson GL, Ham T. Gear selectivity of large-mesh nets and drumnlines used to catch sharks in the Queensland Shark Control Program. Afr J Mar Sci 2011; 33: 37-43.

[29] Towner AV, Wcisel MA, Reisinger RR, Edwards D, Jewell OJ. Gauging the threat: The first population estimate for white sharks in South Africa using photo identification and automated software. PloS One 2013; 8(6): e66035.

[30] Robinson AC, Canty PD, Mooney PA, Ruddock PM. South Australia's Offshore Islands. South Australian Department of Environment and Natural Resources 1996, Adelaide.

[31] Heupel MR, Semmens JM, Hobday AJ. Automated acoustic tracking of aquatic animals: scales, design and deployment of listening station arrays. Mar FW Res 2006; 57: 1-13.
[32] Simpfendorfer CA, Heupel MR, Hueter RE. Estimation of short term centers of activity from an array of omnidirectional hydrophones and its use in studying animal movements. Can J Fish Aquat Sci 2002; 59: 23-32.

[33] Lembo G, Spedicato MT, Økland F, et al. A wireless communication system for determining site fidelity of juvenile dusky groupers Epinephelus marginatus (Lowe, 1834) using coded acoustic transmitters. Hydrobiologia 2002; 483: 249-57.

[34] Bradford RW, Bruce BD, McAuley RB, Robinson G. An evaluation of passive acoustic monitoring using satellite communication technology for near real-time detection of tagged animals in a marine setting. The Open Fish Sci J 2011; 4: 10-20.

[35] Bruce BD. White sharks: the biology and ecology of Carcharodon carcharias. In: Pikitch E, Camhi M, Eds: Sharks of the Open Ocean. Blackwell Scientific 2008; pp. 69-81.

[36] Semmens JM, Payne NL, Huveneers C, Sims DW, Bruce BD. Feeding requirements of white sharks may be higher than originally thought. Sci Rep 2013; 3: 1471.

[37] Domeier ML, Nasby-Lucas N. Annual re-sightings of photographically identified white sharks (Carcharodon carcharias) at an eastern Pacific aggregation site (Guadalupe Island, Mexico). Mar Biol 2007; 150(5): 977-84.

[38] Jorgensen SJ, Chapple TK, Anderson S, et al. Connectivity among white shark coastal aggregation areas in the Northeastern Pacific. In: Domeier M, Ed. Global perspectives on the biology and life history of the Great White Shark. CRC Press 2012; pp. 159-68.

[39] Klimley AP, Le Boeuf BJ, Cantara KM, et al. The hunting strategy of white sharks (Carcharodon carcharias) near a seal colony. Mar Biol 2001; 138: 617-36.

[40] DEWNR. Thorny Passage Marine Park Management Plan 2012 [homepage on the internet]. Adelaide, South Australia: Department of Water and Natural Resources [cited 01 July 2014]. Available from http://www.environment.sa.gov.au/marineparks/home

[41] Huveneers C, Rogers PJ, Beckmann C, et al. The effects of cagediving activities on the fine-scale swimming behaviour and space use of white sharks. Mar Biol 2013; 160(11): 2863-75.

(C) Robbins et al.; Licensee Bentham Open.

This is an open access article licensed under the terms of the (https://creativecommons.org/licenses/by/4.0/legalcode), which permits unrestricted, noncommercial use, distribution and reproduction in any medium, provided the work is properly cited. 